\title{
Latency and Persistence of 'Candidatus Liberibacter asiaticus' in Its Psyllid Vector, Diaphorina citri (Hemiptera: Liviidae)
}

\author{
Maria Cristina Canale, Arthur Fernando Tomaseto, Marineia de Lara Haddad, Helvécio Della Coletta-Filho, and \\ João Roberto Spotti Lopes
}

First, second, third, and fifth authors: Department of Entomology and Acarology, Luiz de Queiroz College of Agriculture, University of São Paulo, C.P. 9, Piracicaba, SP, 13.418-900, Brazil; first author: Agricultural Research Company of Santa Catarina State, Epagri, C.P. 791, Chapecó, SC, 89803-904, Brazil; and fourth author: Centro de Citricultura Sylvio Moreira, IAC, C.P. 4, Cordeirópolis, SP, 13490-970, Brazil. Accepted for publication 13 October 2016.

ABSTRACT

\begin{abstract}
Although 'Candidatus Liberibacter asiaticus' (Las) is a major pathogen associated with citrus huanglongbing (HLB), some characteristics of transmission by the psyllid vector Diaphorina citri are not fully understood. We examined the latent period and persistence of transmission of Las by $D$. citri in a series of experiments at $25^{\circ} \mathrm{C}$, in which thirdinstar psyllid nymphs and 1-week-old adults were confined on infected citrus for an acquisition access period (AAP), and submitted to sequential inoculation access periods (IAPs) on healthy citrus seedlings. The median latent period $\left(\mathrm{LP}_{50}\right.$, i.e., acquisition time after which $50 \%$ of the individuals can inoculate) of 16.8 and 17.8 days for psyllids that acquired Las as nymphs and adults, respectively, was determined by transferring single individuals
\end{abstract}

in 48-h IAPs. Inoculation events were intermittent and randomly distributed over the IAPs, but were more frequent after acquisition by nymphs. A minimum latent period of 7 to 10 days was observed by transferring groups of 10 psyllids in 48-h IAPs, after a 96-h AAP by nymphs. Psyllids transmitted for up to 5 weeks, when submitted to sequential 1-week IAPs after a 14-day AAP as nymphs. The long latent period and persistence of transmission are indirect evidences of circulative propagation of Las in D. citri.

Additional keywords: Asian citrus psyllid, citrus greening, prokaryote-vector relationship, retention time.
Huanglongbing (HLB) is one of the world's most serious diseases affecting citrus, causing serious economic losses (Bové 2006; Gottwald 2010). There are three phloem-limited $\alpha$-proteobacteria associated with HLB, 'Candidatus Liberibacter asiaticus' (Las), ' $C a$. L. americanus', and ' $\mathrm{Ca}$. L. africanus', which were originally reported in Asia, Brazil and Africa, respectively (Bové 2006; Teixeira et al. 2005). Nowadays, Las is widely spread and the most prevalent species associated with the disease in tropical and subtropical regions of Asia and Americas (Hall and Gottwald 2011). Characteristic symptoms of HLB include blotchy mottled leaves and yellowing shoots, vein corking and dieback. As the disease advance, fruit becomes unmarketable and tree death eventually occurs (Bové 2006; Da Graça 1991).

HLB-associated liberibacters are transmitted by graft propagation of infected citrus tissue and by psyllid vectors. Globally, the Asian citrus psyllid, Diaphorina citri Kuwayama (Hemiptera: Liviidae) is the most important vector because of its wide distribution and prevalence in most citrus growing regions (Grafton-Cardwell et al. 2013; Hall et al. 2013). Because of the lack of resistant citrus varieties, HLB control depends on preventive measures including vector control and removal of infected trees in affected orchards, as well as the use of healthy nursery trees for new plantings (Belasque and Bassanezi 2010; Hall et al. 2013).

D. citri is thought to transmit Las in a persistent propagative manner because the bacterium is found in various insect organs and tissues, including midgut, hemocoele, fat body, ovaries, and salivary glands (Ammar et al. 2011b; Xu et al. 1988). An increase in titers is found over time when acquired by nymphs (Ammar et al. 2011a; Inoue et al.

Corresponding author: J. R. S. Lopes; E-mail address: jrslopes@usp.br

*The $\boldsymbol{e}$-Xtra logo stands for "electronic extra" and indicates that three supplementary tables are published online.

(c) 2017 The American Phytopathological Society
2009). It is well documented that $D$. citri nymphs acquire Las more efficiently than adults, and are able to transmit the pathogen in late instars or after their emergence as adults (Inoue et al. 2009; PelzStelinski et al. 2010; Xu et al. 1988). The pathogen can be acquired by adult $D$. citri after 15 to 30 min of feeding on an infected plant (Capoor et al. 1974). Efficient acquisition requires longer feeding periods (Pelz-Stelinski et al. 2010). After acquisition, Las can be detected in the psyllids throughout their lives (Hung et al. 2004; Xu et al. 1988).

Other phloem-limited bacteria transmitted by hemipterans, such as plant-pathogenic mollicutes (phytoplasmas and spiroplasmas), propagate in various internal organs of their insect vectors, typically show a latency of several days or weeks and persist up to insect death (Hogenhout et al. 2008; Orlovskis et al. 2015; Purcell 1982; Weintraub and Beanland 2006). Latency is the period required for a vector to be able to inoculate a plant with a pathogen after its acquisition from a source plant (Purcell 1982). It is measurable and considered accomplished when the insect transmits the pathogen for the first time to healthy plants following acquisition (Murral et al. 1996).

Despite the evidences for a propagative vector-pathogen relationship, information about the latency of Las in D. citri is inconsistent, with latent periods varying widely (1 to 25 days) (Capoor et al. 1974; Da Graça 1991; Xu et al. 1988). The inconsistencies may be partially explained because experiments have been conducted under different environmental conditions and by the lack of sensitive methods for detection of liberibacter infection since diagnosis was based primarily on HLB symptoms.

With the development of sensitive quantitative real-time polymerase chain reaction (qPCR)-based assays, detection of liberibacters in plants and insects has become more reliable (Ammar et al. 2013b; Pelz-Stelinski et al. 2010; Wang et al. 2006). Recently, Pelz-Stelinski et al. (2010) attempted to determine the latent period of Las in $D$. citri by serial transmission after acquisition by adults, but no transmission was observed (no symptoms of HLB 1 year after inoculation and Las was not detected by qPCR). Low acquisition and transmission rates of Las by psyllid adults are additional factors 
that make determination of latency a difficult task (Pelz-Stelinski et al. 2010). Therefore, new studies using qPCR under standardized conditions are needed to determine transmission characteristics. More recently, Sengoda et al. (2014) reported a latency of 2 weeks for transmission of 'Candidatus Liberibacter solanacearum', the putative causal agent of potato zebra chip, by the potato psyllid, Bactericera cockerelli (Sulc) (Hemiptera: Triozidae).

In this paper, the latent period for Las after acquisition by nymphs and adults of a Brazilian population of $D$. citri has been estimated, acquisition and transmission rates analyzed, and the intermittence and persistence of Las transmission verified. Quantification of the latent period contributes to a better understanding of epidemiology and may aid in the timing of insecticide applications (Sengoda et al. 2014).

\section{MATERIALS AND METHODS}

Plant and insect materials. Psyllids were reared inside screened cages with aluminum frames $(35 \times 35 \times 53 \mathrm{~cm})$ and acrylic doors, in a climate-controlled room $\left(25 \pm 2{ }^{\circ} \mathrm{C}, 70 \pm 10 \%\right.$ relative humidity and $14 \mathrm{~h} \mathrm{light} / 10 \mathrm{~h}$ dark photoperiod), under fluorescent coolwhite light bulbs (80 W) (Parra et al. 2010). Insects were maintained on orange jasmine (Murraya paniculata [Rutaceae]) and tested regularly by qPCR to confirm that the colony remained free of liberibacter.
One- to two-year-old HLB-symptomatic sweet orange plants (Citrus sinensis (L.) Osbeck, 'Pêra') were used in the experiments as the source of inoculum of Las. The presence of the bacterium in individual branches of the source plants was confirmed by qPCR before they were used for acquisition access periods (AAP) of Las by psyllids. Healthy sweet orange plants ( $C$. sinensis 'Pêra') grown from seeds (hereafter referred as seedlings) were used as test plants for inoculation by psyllids; they were pruned 2 weeks before the experiments to approximately $8 \mathrm{~cm}$ tall, and showed young leaves when exposed to the psyllids. For all experiments, acquisition and inoculation were performed at $25^{\circ} \mathrm{C}$ in the climate-controlled room.

Median latent period ( $\left.\mathbf{L} \mathbf{P}_{\mathbf{5 0}}\right)$. Groups of third-instar nymphs and 1-week-old adults were enclosed in mesh bags on young shoots of source plants for Las acquisition during a 48-h AAP. This experiment included 18 psyllids that acquired Las as nymphs and 20 as adults in a first trial, and 35 psyllids that acquired the bacterium as nymphs and 31 as adults in a second trial. Next, insects of each age group were individually transferred to healthy sweet orange seedlings (test plants) into cages constructed with 50-ml Falcon conical tubes (Corning Incorporated, NY) for successive 48-h inoculation access periods (IAP). After a 48-h IAP, each psyllid was transferred to another test plant for the following IAP and so on; these serial transfers occurred until 35 and 31 days after start of the

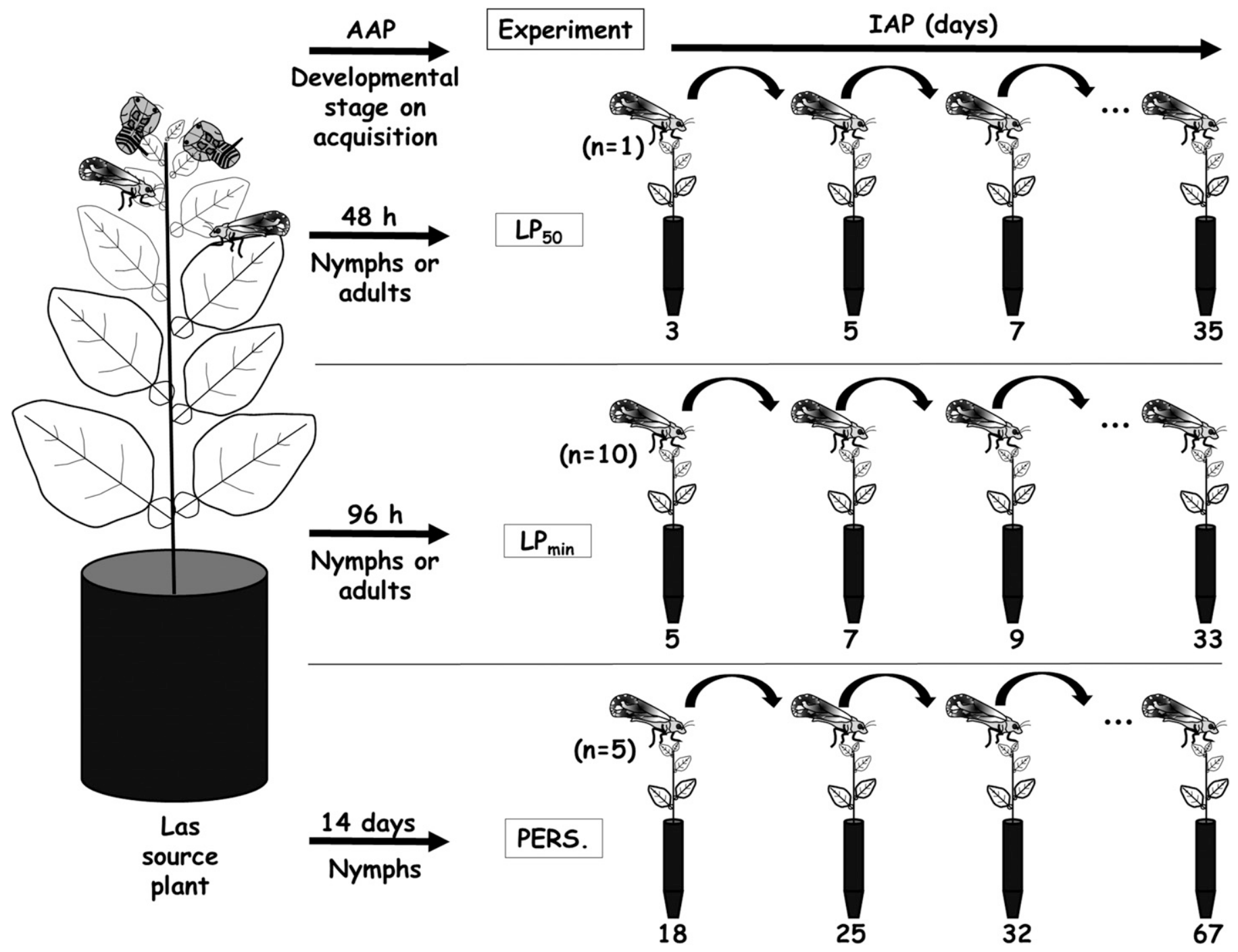

Fig. 1. Schematic illustration of experiments to determine median latent period ( $\left.\mathrm{LP}_{50}\right)$, minimum latent period (LP $\mathrm{P}_{\mathrm{min}}$ ), and persistence (PERS.) of 'Candidatus Liberibacter asiaticus' (Las) in Diaphorina citri. After an acquisition access period (AAP) on a Las source plant, single insects $(n=1)$ or a group of insects $(n=10$ or 5$)$ were serially transferred to healthy citrus seedlings (test plants) for successive inoculation access periods (IAP). The number indicated for each IAP represents its midpoint (and the number of days after the beginning of the AAP). 
acquisition for trials 1 and 2, respectively (Fig. 1). Each psyllid was tested for the presence of Las by qPCR after its last IAP.

The $\mathrm{LP}_{50}$ was defined as the period between the start of the AAP and the midpoint of the 48-h IAP in which $50 \%$ of the vectors transmitted Las for the first time. For the negative control, 10 adults and 10 nymphs (third instar) from the same rearing cage were caged directly on healthy sweet orange seedlings ( 1 individual per plant) and serially transferred as described for psyllids that received the 48-h AAP.

Minimum latent period $\left(\mathbf{L P}_{\min }\right)$. The $\mathrm{LP}_{\min }$ was defined as the time elapsed between the start of the AAP and the midpoint of the IAP in which the first transmission event occurred in a cohort of vectors, and investigated by serially transferring (see above) a larger number of psyllids to the test plants. Groups of third instar nymphs and 1-week old adults were confined on Las source plants for a 96-h AAP. Next, insects of each development stage were divided into groups of 10 individuals and serially transferred 15 times to new healthy sweet citrus seedlings for 48-h IAPs (Fig. 1). Thirteen groups of each age were evaluated, totaling 130 individuals. If an insect died during the first four transfers, it was replaced with reserve individuals from the same AAP batch and age group, which were held simultaneously on healthy citrus seedlings in the same climate-controlled room. For the negative control, 20 adults and 20 nymphs (third instar) from the same rearing cage were caged directly on healthy sweet orange seedlings (10 psyllids per plant) and serially transferred as described for psyllids that were submitted to the 96-h AAP. The occurrence of insect mortality was scored after each IAP; the survivors at the end of the experiment were tested individually by qPCR for Las and the acquisition rate estimated.

Persistence of transmission and retention of Las by $D$. citri adults. Third-instar nymphs were confined on young shoots of a Las-infected plant (source plant) for an AAP of 14 days. The psyllids (now adults) were then serially transferred to healthy sweet orange seedlings (test plants), in groups of five insects per seedling, for eight successive 1-week IAPs (Fig. 1). For the negative control, 1 -week-old adults of $D$. citri that emerged from the same rearing cage were confined directly on the healthy sweet orange seedlings (five psyllids per test plant), and then serially transferred as described for the psyllids that were previously submitted for Las acquisition on the source plant. After each IAP, 10 psyllids were tested for the presence of Las by qPCR. These psyllids were sampled from a reserve group from the same AAP batch and age, which were simultaneously held on healthy citrus seedlings in the same climatecontrolled room. The experiment was repeated five independent times, with 10 groups of five insects in each repetition, except in the fifth one, which started with 30 groups.

HLB symptom evaluation and leaf sampling for qPCR analyses. After each IAP, the test plants were transplanted to 2-liter pots and transferred to a vector-proof screened greenhouse, where they were treated weekly with macro and micronutrient fertilizer, and fortnightly with insecticides. Between 4 and 10 months postinoculation, all test plants were inspected for the presence of HLB symptoms and samples of five leaves from different parts of each plant taken for detection of Las by qPCR. A test plant was considered symptomatic when presented at least one of the following HLB characteristic symptoms: yellow shoots, older leaves with blotchy mottle, vein corking. Plants not showing characteristic symptoms were tested at least twice by qPCR during the inspection period to confirm infections.

DNA extraction from plant and insect tissue. Total DNA from citrus leaves was extracted using a modified cetyltrimethylammonium bromide (CTAB) method (Coletta-Filho et al. 2014; Murray and Thompson 1980). Petioles and midveins from five leaves from the same plant were chopped, and $200 \mathrm{mg}$ was macerated in $800 \mu \mathrm{l}$ of extraction buffer (100 mM Tris- $\mathrm{HCl}, \mathrm{pH} 7.5,50 \mathrm{mM}$ EDTA, and $500 \mathrm{mM} \mathrm{NaCl}$ ) using a mortar and pestle. Each sample was transferred to a $2.0 \mathrm{ml}$ microtube and $500 \mu \mathrm{l}$ of CTAB buffer (5\% CTAB, $10 \% \mathrm{PVP}$, and $140 \mathrm{mM}$ mercaptoethanol) was added. The mixture was maintained at $65^{\circ} \mathrm{C}$ for $30 \mathrm{~min}$ and then centrifuged for $5 \mathrm{~min}$ at $3,500 \mathrm{rpm}$. The supernatant was transferred into a $1.5 \mathrm{ml}$ microtube with chloroform/isoamyl alcohol 24:1 and centrifuged at 11,700 rpm for $5 \mathrm{~min}$. The next day isopropanol was added and the precipitated DNA pellet was washed with $500 \mu \mathrm{l}$ of $70 \%$ ethanol. DNA was eluted in $50 \mu \mathrm{l}$ of $\mathrm{ddH}_{2} \mathrm{O}$ (Millipore) and after a brief spin, the extract was stored at $-20^{\circ} \mathrm{C}$ for Las testing by qPCR.

At the end of each $\mathrm{LP}_{50}$ and $\mathrm{LP}_{\min }$ trial, D. citri were collected and immediately stored in $80 \%$ ethanol at $-20^{\circ} \mathrm{C}$ for Las testing. Total DNA extraction from individual psyllids was done according to the methods described by Coletta-Filho et al. (2014). Each insect was crushed in $30 \mu \mathrm{l}$ of STE buffer $(10 \mathrm{mM}$ Tris-HCl, $1 \mathrm{mM}$ EDTA, and $25 \mathrm{mM} \mathrm{NaCl}$ ) in a $1.5 \mathrm{ml}$ microtube using a pestle. Then, $15 \mu \mathrm{l}$ of proteinase $\mathrm{K}(200 \mu \mathrm{g} / \mathrm{ml})$ was added and the samples were incubated at $56^{\circ} \mathrm{C}$ for $30 \mathrm{~min}$. DNA was purified using a Wizard Genomic DNA Purification Kit (Promega Corporation, Madison, WI). DNA was centrifuged at $13,450 \times g$ for 3 min and isopropanol was then added. The next day DNA pellets were washed with $150 \mu \mathrm{l}$ of $70 \%$ ethanol. Total DNA was eluted in a final volume of $50 \mu \mathrm{l}$ of elution buffer (10 mM Tris, $1 \mathrm{mM}$ EDTA, $20 \mu \mathrm{g} \mu \mathrm{l}^{-1}$ RNAse) and stored at $-20^{\circ} \mathrm{C}$ before Las testing by qPCR.

qPCR. Las detection in insect and plant tissues was done by qPCR using primers and probe designed to the 16S rDNA of Las (Coletta-Filho et al. 2010). The reaction mix (13 $\mu \mathrm{l})$ contained $0.4 \mu \mathrm{M}$ of each forward and reverse primer, $0.2 \mu \mathrm{M}$ of TaqMan MGB probe, $6.5 \mu$ l of TaqMan Fast Universal PCR Master Mix (2x), and 3 or $4 \mu \mathrm{l}$ of total DNA from plant or insect, respectively. The reagents were from Life Technologies (Foster City, CA). The amplifications, data acquisition, and data analyses were run on a 96-well ABI PRISM 7500 Fast Sequence Detection System using the default for cycle amplification. Each run comprised two plate wells (replicates) per sample of tested DNA, negative and positive controls, and nontemplate control.

Standard curve for qPCR. An amplicon from 16S rDNA of Las $(\sim 1,200$ bp) was generated with the primer pair OI1 and OI2c (Hocquellet et al. 1999), inserted in pGEM-T recombinant plasmid (Promega Corporation, Madison, WI) and cloned into competent E. coli strain DH5 $\alpha$. The quantification of Las, based on the copy number of the target gene, was done as described by Wang et al. (2006). The plasmid solution was 10 -fold serially diluted from $90 \mathrm{ng}^{\mathrm{l}-1}\left(1.90 \times 10^{10}\right.$ copy number $)$ to $0.09 \mathrm{fg} \mathrm{Il}^{-1}\left(1.9 \times 10^{1}\right.$ copy number), and the qPCR assay was run by adding at each dilution point $100 \mathrm{ng}$ of total DNA from healthy citrus plants. These standard dilutions were used to establish the calibration curve by plotting the cycle threshold $(\mathrm{Ct})$ value ( $y$ axis) against the $\log _{10}$ of the copy number of the 16S rDNA gene ( $x$ axis). A highly significant inverse linear relationship was obtained between the $\mathrm{Ct}$ values and the amount of 16S rDNA copy input, described by the regression equation $y=-2.0016 \times \log (16 \mathrm{~S}$ rDNA copy number $)+35.83, R^{2}=$ 0.9969 . Based on this standard curve, qPCR reactions were considered positive if the mean $\mathrm{Ct}$ was $\leq 35$.

Data analysis. A transmission event was confirmed when a test plant was Las-positive by qPCR between 4 and 10 months after inoculation. $\mathrm{LP}_{50}$ was estimated by transforming the cumulative percentage of first transmissions to probit and the midpoint of the transfer interval in days to logarithms, calculating a least squares linear regression (Sylvester 1965). Linear regression and Pearson's correlation coefficient were used to assess probits of cumulative first transmission and log of time (days). A log-probit transformation serve to plot the data around a straight line, solving the value of time when the probit value of the cumulative percentage of first transmission was equal to 5 (Sylvester 1965). The slopes of probit regression lines from nymphs and adults were compared using a $t$ test $(P<0.05)$. Only psyllids that transmitted once or more were included in the $\mathrm{LP}_{50}$ analysis for the two treatments (acquisition either by nymphs or adults).

The transmission pattern by individual psyllids from the $\mathrm{LP}_{50}$ experiment was examined for randomness or clustering by ordinary runs analysis (Madden 1982), as described by Murral et al. (1996). If insects transmit Las from plant to plant successively, few runs 
would be expected due to the high transmission rates. In contrast, if insects inoculate one plant and not successive ones and maybe inoculate again at a later IAP, a random mixing of healthy and infected plants and, consequently, a larger number of runs would be expected. The null hypothesis is that the sequence of infected plants is random $(P>0.05)$ and the alternative hypothesis is that the sequence is clustered (Madden 1982). Only psyllids that transmitted once or more were included in the analysis.

By pooling data from the two trials of the $\mathrm{LP}_{50}$ experiment, the percentage of psyllids that transmitted Las out of the total number of individuals submitted to acquisition as nymphs or adults was calculated. In addition, a transmission rate for each IAP interval was calculated for the nymph and adult treatments, represented by the proportion of psyllids that transmitted Las out of the total number of live psyllids tested at each IAP. The acquisition rate, which is the proportion of insects that acquired Las (qPCR-positive) out of the total submitted to acquisition, was calculated only for trial 2.

For the $\mathrm{LP}_{\min }$ and persistence experiments, which involved serial transfers of groups of insects, transmission rate by single insects $(p)$ during each IAP was estimated by the formula $p=1-(1-I)^{1 / k}$, where $I$ is the proportion of infected plants in each IAP and $k$ is the number of living insects at each IAP per plant (Swallow 1985). The parameter $p$ represents the probability of transmission to test plants when inoculated using one insect per plant, allowing comparisons of transmission efficiency among experiments or treatments in which the test plants are inoculated with different numbers of vectors. Pearson's correlation between psyllid survival and estimated transmission rates for single insect $(p)$ over time were conducted for the $\mathrm{LP}_{\text {min }}$ experiment. Furthermore, a survival distribution was fitted to psyllid survival data using the Kaplan-Meier method.

Probit $\mathrm{LP}_{50}$ estimation, Pearson's correlations, and comparison of regression slopes were performed using the SAS 9.3 TS software (SAS Institute Inc., Cary, NC). Survival analyses were performed by statistical software R v.3.2.3 (The R Foundation for Statistical Computing, Vienna, Austria) using the survfit function of survival package.

\section{RESULTS}

$\mathbf{L P}_{\text {50. }}$. The acquisition rates of Las in the second trial, estimated from qPCR-positive insects, were $74.3 \%$ ( 26 qPCR-positive insects of 35 tested) and $51.6 \%$ (16 insects out of 31 tested) for nymphs and adults, respectively. Most inoculated plants that tested positive for Las by qPCR showed mild or moderate leaf mottle between 5 and 10 months postinoculation. None of the negative control plants tested Las-positive by qPCR or showed HLB-like symptoms.

The percentage of psyllids that transmitted Las at least once in both trials was lower after acquisition as 1-week old adults $(11.8 \%$; i.e., 6 individuals transmitted Las out of 51 tested) than as thirdinstar nymphs (43.4\%; i.e., 23 individuals transmitted Las out of 53 tested). Las transmission by the six adult psyllids that acquired Las as adults was detected once for each psyllid at 11, 13, 15, 29, 31, and 33 days after beginning of AAP (Table 1). When Las was acquired by third-instar nymphs, the first transmission event was detected at 9 (trial 2) and 11 (trial 1) days from the beginning of the AAP (Table 2). The data from trials 1 and 2 for nymph acquisition show that the first transmission events occurred between the 9th and the 31 st day. In total, 23 insects inoculated the plants with Las and 8 of them transmitted Las more than once (insect numbers 2, 5, 8, and 12 inoculated twice; 10 and 20 inoculated three times; 6 and 15 inoculated four times).

Transmission rates of Las by individual psyllids at each IAP, following acquisition by nymphs, varied from 0 to $20 \%$ (Table 2), with a mean of $8.2 \%$ for sequential transfers between 9 and 31 days after AAP onset. The transmission pattern through time by individual psyllids was intermittent. Ordinary runs analyses were performed on the series in which psyllids survived 15 transfers and at least one transmission event was observed (Table 2). The analyses showed that Las transmission events occurred randomly over time $(P>0.05)$, usually separated by one or more IAPs in which the psyllids failed to transmit. Insufficient number of transmitting individuals that acquired the bacterium as adults precluded the analysis.

For estimation of $\mathrm{LP}_{50}$ we assumed that the inoculation of test plants occurred at the midpoint of each transfer interval. By pooling the data of trials 1 and 2, cumulative percentages of the first transmission by psyllids that acquired Las as nymphs or as adults were plotted over time after the onset of the AAP (Fig. 2). Using a probit/log transformation of the data (Fig. 3), but excluding those insect series in which no transmission event was detected or the insect died before the fourth transfer, the $\mathrm{LP}_{50}$ was 16.8 and 17.8 days for acquisition by nymphs and adults, respectively, and the regression slopes were significantly different (Table 3).

$\mathbf{L P}_{\text {min }}$. All groups of D. citri that acquired Las as third instar nymphs initiated the transmission of Las to test plants at 11 days after the beginning of the AAP, except for group 13, which began transmitting Las 13 days after the AAP (Table 4). Transmission was detected until the last IAP, at 33 days after AAP. Very few transmission events were recorded for insects that acquired Las as adults, despite using 13 groups of 10 insects per test plant. Only two of these groups were able to transmit the bacterium; one of them inoculated only at 30 days after the beginning of AAP and other group inoculated twice, at 12 and 32 days (data not shown).

Insects that survived the 15 serial transfers were tested for Las by qPCR. By the end of the last IAP, there were 50 survivors from the groups that acquired Las as nymphs (92\% Las-positive) and 81 survivors from the groups that acquired the bacterium as adults

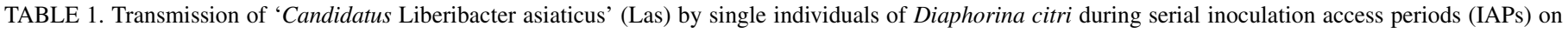
healthy sweet orange seedlings at $25^{\circ} \mathrm{C}$, after acquisition as adults

\begin{tabular}{|c|c|c|c|c|c|c|c|c|c|c|c|c|c|c|c|c|c|c|c|}
\hline \multirow[b]{2}{*}{ Trial } & \multirow[b]{2}{*}{ Psyllid } & \multicolumn{18}{|c|}{ Days after the beginning of AAPy } \\
\hline & & 3 & 5 & 7 & 9 & 11 & 13 & 15 & 17 & 19 & 21 & 23 & 25 & 27 & 29 & 31 & 33 & 35 & 37 \\
\hline \multirow[t]{5}{*}{1} & 1 & - & - & - & - & - & - & + & - & - & - & - & - & - & - & - & $\mathrm{D}$ & & \\
\hline & 2 & - & - & - & - & - & - & - & - & - & - & - & - & - & + & - & - & - & - \\
\hline & 3 & - & - & - & - & - & + & - & $\mathrm{D}$ & & & & & & & & & & \\
\hline & 4 & - & - & - & - & - & - & - & - & - & - & - & - & - & - & - & + & - & - \\
\hline & 5 & - & - & - & - & - & - & - & - & - & - & - & - & - & - & + & - & - & - \\
\hline 2 & 6 & - & - & - & - & + & - & - & - & - & - & - & - & - & - & - & - & & \\
\hline \multicolumn{15}{|c|}{ Transmission } & 2.9 & 3.0 & 5.6 & 0.0 & 0.0 \\
\hline
\end{tabular}

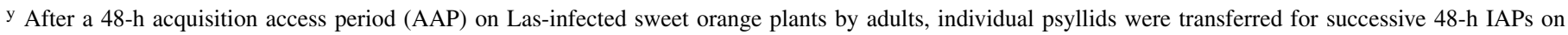
healthy test seedlings. The number of days after the beginning of the AAP represents the midpoint of each IAP. Plus (+), minus (-), and D symbols indicate transmission, no transmission, and insect death, respectively. Only individuals that transmitted Las were included in this table.

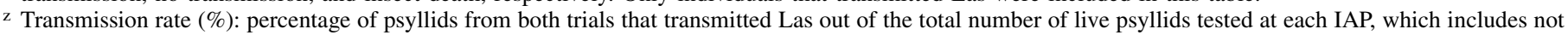
only the individuals listed in this table but also those that did not transmit Las anytime. The experiment started with 20 individuals in trial 1 and 31 in trial 2 ; the total number of psyllids decreased over time due to mortality (Supplementary Table S1). 
(57\% Las-positive). All inoculated test plants that were Las-positive by qPCR showed typical HLB symptoms by 5 months after inoculation, such as a blotchy mottle on the leaves, cork veins and yellow shoots. None of the negative control plants were positive for Las by qPCR or showed HLB symptoms.

The transmission rate by single insects $(p)$ that acquired Las as nymphs was estimated for each sequential 48-h IAP transfer using groups of psyllids, beginning at 11 days after the onset of the AAP, when the first transmission events were detected. Estimated transmission rates $(p)$ ranged from 0 to $22.3 \%$ (Fig. 4). The mean transmission rate for sequential transfers between 11 and 33 days after AAP onset was $6.4 \%$. The transmission rate by single insects ( $p$ ) was not calculated at 13 days after the beginning of the AAP (Fig. 4), because all test plants inoculated in that particular IAP became infected $(I=1.0)$, precluding an unbiased estimation of this parameter (Swallow 1985). There was no significant correlation $(r=$ $0.61 ; P=0.0793)$ between transmission rate by single insects $(p)$ and psyllid survival along time (days) (Fig. 4). Despite the increasing mortality of the insects, the transmission rates by single insects remained relatively stable throughout the IAP transfers.

Persistence of transmission by $D$. citri. This experiment of five repetitions started with a total of 350 psyllids on 70 test plants (five psyllids per plant) in the first week following a 14-day AAP, and ended up with 75 insects on 15 plants at the eighth week as insects died. The acquisition rate, measured by the mean percentage of qPCR-positive psyllids by the end of the 14-day AAP, was $48 \%$. The percentage of Las-positive psyllids increased to roughly $70 \%$ in the 1st and 2nd weeks after the AAP, remained stable at 75 to $80 \%$ between the $3 \mathrm{rd}$ and 5 th weeks, and dropped to approximately $40 \%$ during the 6 th, 7 th and 8 th weeks (Fig. 5). The psyllids were able to transmit Las for up to 5 weeks after the AAP, and the mean transmission rates, which were calculated with estimated transmission rates by single psyllids $(p)$ from five replicates, ranged from 1.9 to $4.1 \%$ between the 1 st and the 5 th weeks (Fig. 5). No transmission to test plants was recorded at 6,7 , and 8 weeks postacquisition, when adult psyllids were older than 40 days and a significant proportion (around 50 to $75 \%$ ) of the original population had died (data no shown). Some of the Las-positive test plants diagnosed by qPCR developed HLB symptoms such as blotchy mottle leaves, cork veins, and/or yellow shoots, whereas others showed moderate HLB-like mottle symptom; qPCR Las-positive test plants not showing any symptoms were considered as infected for data analysis.

\section{DISCUSSION}

Insect-borne phytopathogenic bacteria have different modes of transmission. Some groups of phloem-limited bacteria, e.g., phytoplasmas and spiroplasmas invade the vector's digestive tract after acquisition from an infected plant by ingestion and propagate in various internal organs, including salivary glands, from where they can be inoculated into healthy plants (Orlovskis et al. 2015; Purcell 1982). In contrast, the xylem-inhabiting bacterium Xylella fastidiosa is noncirculative in its leafhopper vectors, with retention and propagation sites restricted to the foregut (Purcell and Finlay 1979), and inoculation is thought to occur through egestion (Backus et al. 2015). An important difference between these two modes of transmission is the latent period, which is absent for $X$. fastidiosa (Purcell and Finlay 1979), and long (weeks) for the mollicutes (Weintraub and Beanland 2006), due to the circulative-propagative nature of the relationship in the latter case.

Like mollicutes, liberibacters are phloem-limited bacteria that invade several vector organs, including the filter chamber, midgut, Malpighian tubules, hemolymph, in muscle and fat tissues, ovaries, and salivary glands (Ammar et al. 2011b), thus are expected to exhibit a latent period between acquisition and inoculation. The

TABLE 2. Transmission of 'Candidatus Liberibacter asiaticus' (Las) by single individuals of Diaphorina citri during serial inoculation access periods (IAPs) on healthy sweet orange seedlings at $25^{\circ} \mathrm{C}$, after acquisition as nymphs

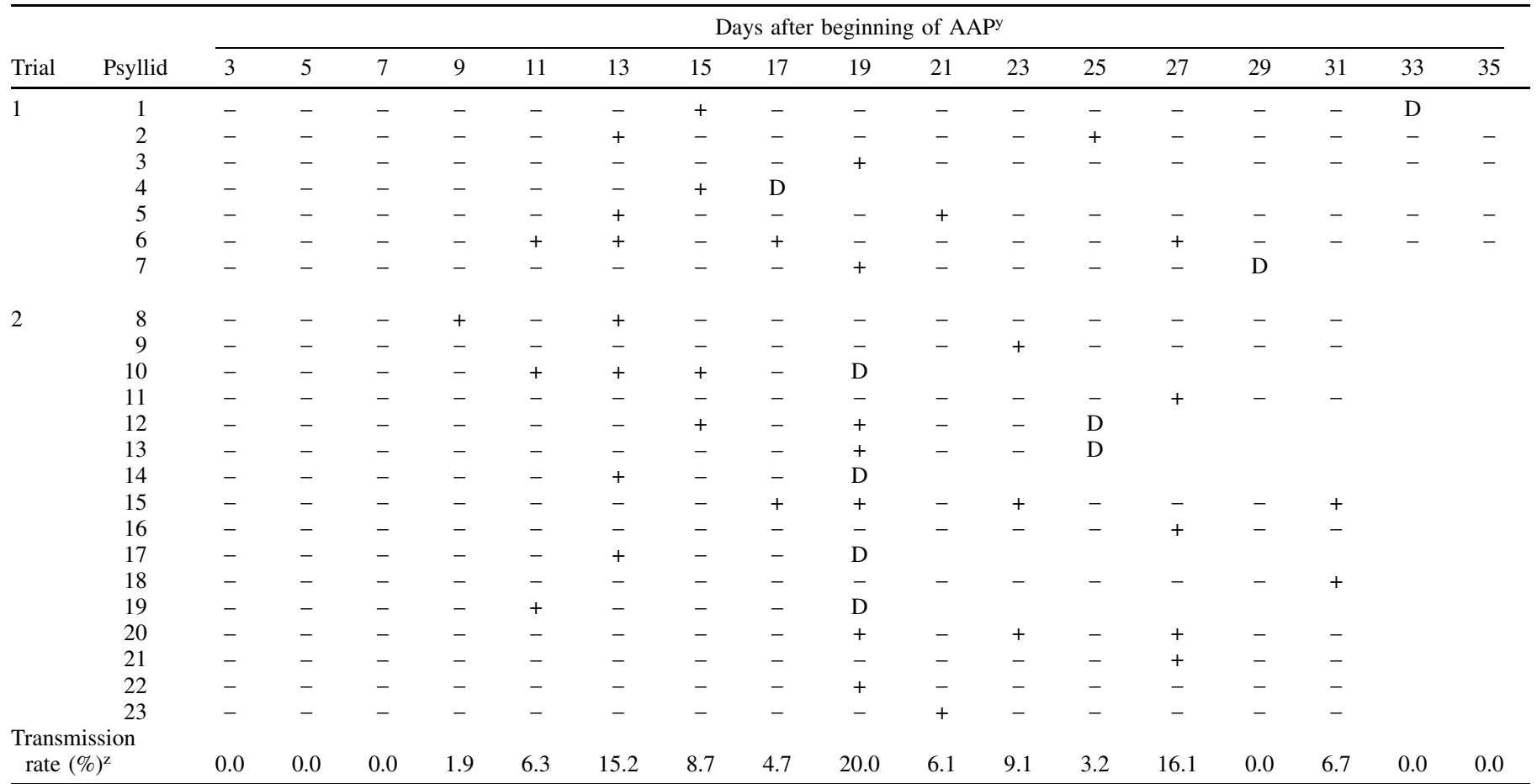

y After a 48-h acquisition access period (AAP) on Las-infected sweet orange plants by third instar nymphs, individual psyllids were transferred for successive 48-h IAPs on healthy test seedlings. The number of days after the beginning of the AAP represents the midpoint of each IAP. Plus (+), minus (-), and D symbols indicate transmission, no transmission, and insect death, respectively. Only individuals that transmitted Las were included in this table.

$\mathrm{z}$ Transmission rate (\%): percentage of psyllids from both trials that transmitted Las out of the total number of live psyllids tested at each IAP, which includes not only the individuals listed in this table but also those that did not transmit Las anytime. The experiment started with 18 individuals in trial 1 and 35 in trial 2 ; the total number of psyllids decreased over time due to mortality (Supplementary Table S2). 
relatively long $\mathrm{LP}_{50}$ estimated for Las after acquisition by thirdinstar nymphs (16.8 days) and 1-week-old adults (17.8 days) of D. citri in the present study supports the hypothesis of circulative propagation. Propagative vector-borne viruses, for example, typically show long median latent periods ( 6 to 31 days), whereas circulative (nonpropagative) viruses complete the latency in their vectors in just a few hours or days (Nault 1997).

The latency duration of Las in D. citri has been investigated in previous studies, but the results were variable. Xu et al. (1988) reported latent periods ranging from $24 \mathrm{~h}$ to 25 days, while Da Graça (1991) reported between 8 to 12 days and Capoor et al. (1974)

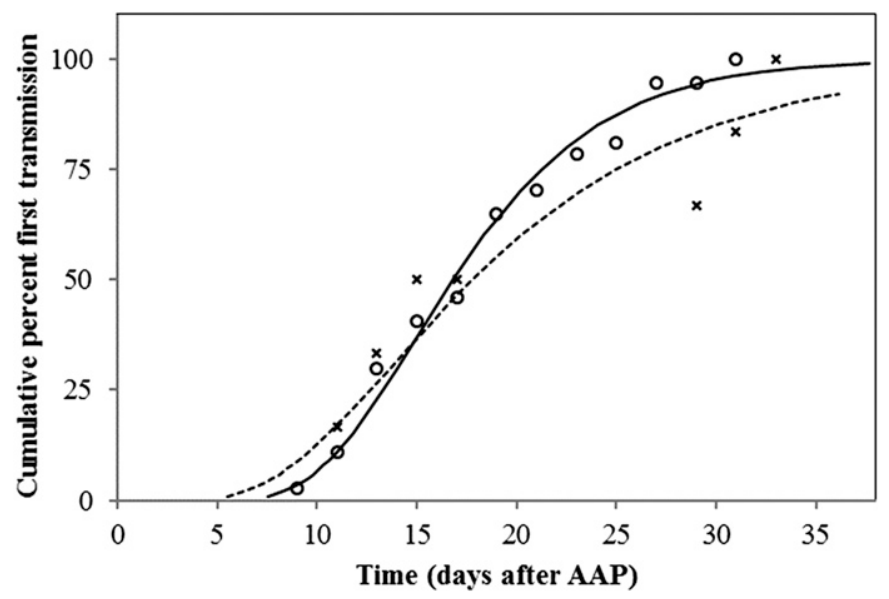

Fig. 2. Cumulative percentage of Diaphorina citri transmitting 'Candidatus Liberibacter asiaticus' (Las) for the first time at $25^{\circ} \mathrm{C}$. After a 48 -h acquisition access period (AAP) on Las source plants as third instar nymphs (solid line and open circles) or 1-week-old adults (dotted line and $\times$ ), the insects were singly transferred to successive 48-h inoculation access periods (IAPs) on healthy sweet orange seedlings. The number of days after the beginning of the AAP represents the midpoint of each IAP. The cumulative percentage of first transmission represents the cumulative number of individuals that transmitted Las for the first time out of the total that transmitted Las; it only takes into account the psyllid series in which a transmission event was observed.

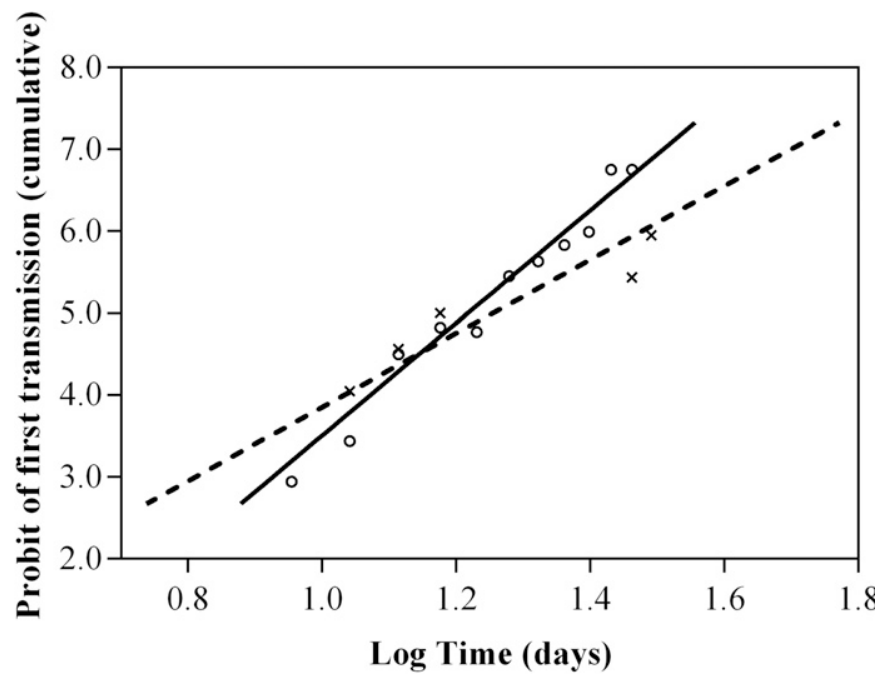

Fig. 3. Log-probit regression analysis of the cumulative frequency of first transmission over time used to estimate the median latent period $\left(\mathrm{LP}_{50}\right)$ of 'Candidatus Liberibacter asiaticus' (Las) in Diaphorina citri, at $25^{\circ} \mathrm{C}$. After a 48 -h acquisition access period (AAP) on Las source plants as third instar nymphs or 1-week-old adults, the insects were singly transferred to successive 48-h inoculation access periods (IAPs) on healthy sweet orange seedlings. Solid line and open circles are, respectively, estimated and observed values following acquisition by nymphs (regression equation: $y=6.6580 x-3.1638$ ). Dotted line and $x$ are estimated and observed values after acquisition by adults (regression equation: $y=4.5753 x-$ $0.6512)$.
21 days. This variability may be explained because transmission was based on the expression of disease in plants (i.e., HLB-like symptoms) and that can under or overestimate transmission data. The latency period estimated in this paper for Las is consistent with that obtained by Sengoda et al. (2014), who reported a 2-week latency for transmission of Las by the potato psyllid, B. cockerelli, using qPCR to detect infections.

Experimental conditions, particularly temperature, vector age, variation in strains, and titer of the pathogen acquired can also influence the duration of the latent period of vector-borne prokaryotes (Moya-Raygoza and Nault 1998; Murral et al. 1996; Purcell 1982), and these factors may also partially explain variations in the reported latent periods for HLB-associated bacteria. Our data suggest that the $\mathrm{LP}_{50}$ of Las at $25^{\circ} \mathrm{C}$ varies with the development stage of the psyllid, being 1.5 days less when Las was acquired as nymphs compared with adults. However, these estimates of $\mathrm{LP}_{50}$ were not statistically different because there was an overlap in their 95\% confidence intervals, although the regression slopes were significantly different. There were few transmission events by psyllids that acquired Las as adults, resulting in a much wider confidence interval for this treatment.

Groups of psyllids, as previously proposed by others (Carraro et al. 2001; Maramorosch 1953; Xu et al. 1988), were used to determine the $\mathrm{LP}_{\min }$ to minimize transmission failures by single insects. We also used an extended AAP (4 days), which resulted in higher rates of Las-positive individuals compared with the $\mathrm{LP}_{50}$ experiment. Although this procedure significantly increased the probability of transmission to test plants for psyllids that acquired Las as nymphs (92 and 100\% infected plants at 11 and 13 days postacquisition, respectively), it reduced the precision of the latency period estimates, because the psyllids may have acquired the bacterium anytime between the 1st and the 4th day of the AAP. Therefore, the observation of first transmission events at 11 days postacquisition means that the $\mathrm{LP}_{\min }$ for $D$. citri nymphs is in the range of 7 and 11 days. For a more precise estimate of $\mathrm{LP}_{\min }$, a similar experiment needs to be carried out by using a shorter AAP (ideally $24 \mathrm{~h}$ ).

Transmission rates of Las by single insects at each one of the serial 48-h IAPs in the $\mathrm{LP}_{50}$ and $\mathrm{LP}_{\text {min }}$ experiments varied from zero to $22.3 \%$ for insects that acquired Las as nymphs, with means of 8.2 and 6.4, respectively. Low transmission rates (1.3 to 12.2\%) of Las by individual $D$. citri have been reported before (Ammar et al. 2011a; Huang et al. 1984; Pelz-Stelinski et al. 2010), in spite of high rates of acquisition of the pathogen, as determined by the proportion of qPCR-positive psyllids (Pelz-Stelinski et al. 2010). The occurrence of much lower transmission rates than would be expected from the number of infected vectors is known for other persistently transmitted pathogens (Hogenhout et al. 2008) and in D. citri the salivary gland may represent an important transmission barrier (Ammar et al. 2011a).

In the current work, a lower proportion of individuals were positive for Las by qPCR and fewer transmission events were recorded in the

TABLE 3. Regression slopes and $\mathrm{LP}_{50}$ estimation of transmission of 'Candidatus Liberibacter asiaticus' by Diaphorina citri at $25^{\circ} \mathrm{C}$

\begin{tabular}{lcccc}
\hline & & \multicolumn{2}{c}{ LP $_{50}$ estimation } \\
\cline { 3 - 5 } Developmental stage & Regression slope $^{\mathrm{x}}$ & Mean & \multicolumn{2}{c}{$95 \%$ CI } \\
\hline Nymphs & $6.66(0.52) \mathrm{a}^{\mathrm{z}}$ & 16.8 & 16.0 & 17.7 \\
Adults & $4.58(1.15) \mathrm{b}$ & 17.8 & 13.7 & 23.1 \\
\hline
\end{tabular}

x Slopes estimated by analysis of maximum likelihood parameter of probit transformed cumulative transmission rates over log of time (days). Number in parentheses is the standard error of the slope.

${ }^{y} \mathrm{LP}_{50}$ estimation based on period between the start of acquisition access period (AAP) and the midpoint of the inoculation access period (IAP) in which $50 \%$ of the vectors transmitted for the first time.

${ }^{\mathrm{z}}$ Regression slopes were significantly different according to the $t$ test $(P<$ $0.05)$. 
latency experiments when psyllids acquired Las as adults than as nymphs. During the $\mathrm{LP}_{50}$ experiment, $43.4 \%$ of the insects were able to transmit Las in at least one of the serial 48-h IAPs when Las was acquired as third instar nymphs, compared with only $11.8 \%$ when acquisition occurred in the adult phase. This confirms that the nymphs are more efficient for Las acquisition (Pelz-Stelinski et al. 2010) and that transmission is more efficient when the pathogen is acquired in the nymphal stage (Inoue et al. 2009). Acquisition efficiency of Las by $D$. citri can be related to insect age, as well as to feeding behavior, AAP, age and nutritional condition of plant tissue and the insect feeding site on plant (Ammar et al. 2011a, b; Bonani et al. 2010; Folimonova and Achor 2010; Pelz-Stelinski et al. 2010). Due to the small diameter of the bacterium relative to the width of the insect food canal, it is likely that all $D$. citri development stages can ingest Las when feeding on infected plants (Ammar et al. 2013a; Folimonova and Achor 2010). However, the ability of adults to feed on mature leaves compared with nymphs, which concentrate their feeding activities on young leaves with higher titers of Las than mature leaves, may reduce the probability of adults ingesting viable bacterial cells, and therefore contributing to a lower rate of Las acquisition than nymphs. Oviposition and nymphal development of $D$. citri occurs solely on young flushes, whereas adults can be found on both young and mature leaves (Ammar et al. 2013a; Tsai and Liu 2000). Nevertheless, Las has uneven distribution in planta (Bové 2006). Folimonova and Achor (2010) found larger numbers of liberibacter cells in phloem sieve tubes in tissue samples of citrus HLB-asymptomatic leaves of young flushes, whereas in more advanced stage of the disease, in older leaves, they found that most of Las is present in a nonviable state. Thus, the concentration of nymphal feeding on young leaves and the possibility of encountering more viable Las cells may explain the increased chance of Las acquisition by nymphs, while acquisition by adults might be hampered due to lower chances of finding viable Las cells in older phloem sieve elements.

While feeding behavior of $D$. citri adults might affect their acquisition efficiency, other factors likely contribute to their lower transmission efficiency. Hypothetically, Las depends on successful passage through the gut and propagation in various internal vector organs, including the salivary glands, before it can be transmitted into healthy plants (Ammar et al. 2011a, b). In our $\mathrm{LP}_{50}$ experiment, transmission rates were 4.4 times lower than the acquisition rates when the pathogen was acquired by adults, but only 1.7 times lower when acquired by nymphs. This suggests that other factors besides bacterial uptake from infected plants may determine the observed differences in Las transmission efficiency between nymph and adults, possibly related to infection, propagation and/or escape barriers of the pathogen in internal organs of the vector. More research is needed to investigate the possibility of tissue barriers that restrict Las movement in D. citri adults and nymphs following ingestion.

In a previous study, Pelz-Stelinski et al. (2010) could not determine the latent period of Las in D. citri presumably due to the low inoculation efficiency by individual adult psyllids. They suspected that an insufficient titer of bacteria was inoculated in test plants by single insects and suggested that exposure to multiple psyllids could result in higher pathogen transmission rates. We tried to determine $\mathrm{LP}_{\min }$ by using groups of 10 insects per test plant, but this procedure did not improve the transmission rates for psyllids that acquired Las as adults. For acquisition by nymphs, there was a marked increase in the proportion of infected plants by inoculating plants using multiple psyllids, but not in vector efficiency, since the estimated mean transmission rate by single psyllids $\left(6.4 \%\right.$; $\mathrm{LP}_{\min }$ experiment) using groups of 10 insects was similar to the transmission rate obtained with only one insect per test plant $\left(8.2 \% ; \mathrm{LP}_{50}\right.$ experiment). Interestingly, HLB typical symptoms (e.g., yellow shoots and/or blotchy mottle) were observed in test plants as early

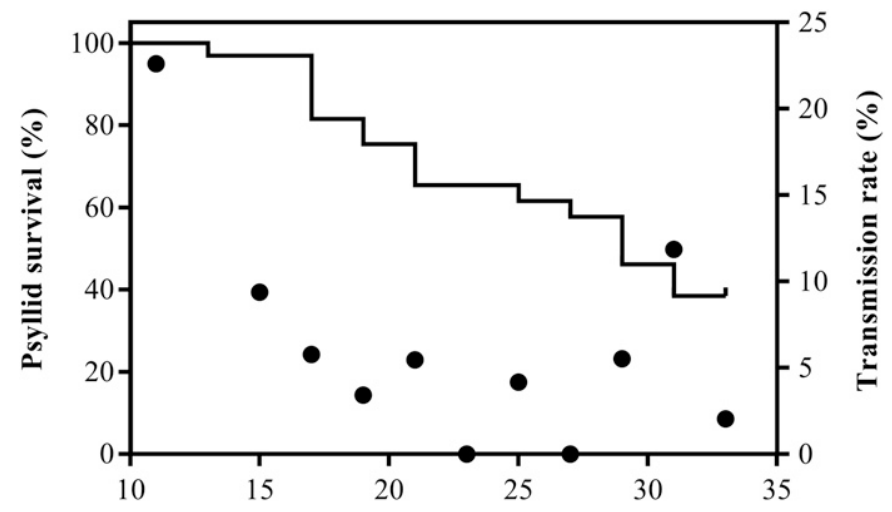

Time (days after AAP)

Fig. 4. Transmission rate of 'Candidatus Liberibacter asiaticus' (Las) by Diaphorina citri individuals (dots) and Kaplan-Meier estimation of psyllid survival (line) during sequential transfers to test plants (days after AAP). Groups of 10 insects $(n=13)$ that acquired Las as third instar nymphs were transferred to successive 48 -h inoculation access periods (IAPs) on healthy sweet orange seedlings at $25^{\circ} \mathrm{C}$. Transmission rates by individual insects $(p)$ during each IAP were estimated as described by Swallow (1985) (see Supplementary Table S3 for original data used in estimation of $p$ ). Time after the beginning of the AAP represents the midpoint of each IAP. Transmission rate for 13th day was not included because all test plants in that transfer were infected, precluding an unbiased estimate.

TABLE 4. Transmission of 'Candidatus Liberibacter asiaticus' (Las) by groups of Diaphorina citri during serial inoculation access periods (IAPs) to healthy sweet orange seedlings at $25^{\circ} \mathrm{C}$, after acquisition by nymphs ${ }^{\mathrm{z}}$

\begin{tabular}{|c|c|c|c|c|c|c|c|c|c|c|c|c|c|c|c|}
\hline \multirow[b]{2}{*}{ Group of psyllids } & \multicolumn{15}{|c|}{ Days after beginning of AAP } \\
\hline & 5 & 7 & 9 & 11 & 13 & 15 & 17 & 19 & 21 & 23 & 25 & 27 & 29 & 31 & 33 \\
\hline 1 & - & - & - & + & + & + & - & - & - & - & - & - & - & - & + \\
\hline 2 & - & - & - & + & + & + & - & - & - & - & - & - & - & - & - \\
\hline 3 & - & - & - & + & + & + & - & - & - & - & - & - & - & - & - \\
\hline 4 & - & - & - & + & + & + & + & - & + & - & - & - & - & + & - \\
\hline 5 & - & - & - & + & + & + & - & + & + & - & + & - & - & - & - \\
\hline 6 & - & - & - & + & + & - & - & - & - & - & - & - & - & + & - \\
\hline 7 & - & - & - & + & + & + & - & - & - & - & - & - & - & - & - \\
\hline 8 & - & - & - & + & + & + & + & - & + & - & - & - & + & + & - \\
\hline 9 & - & - & - & + & + & - & - & + & - & - & - & - & + & - & - \\
\hline 10 & - & - & - & + & + & - & - & + & - & - & + & - & - & + & - \\
\hline 11 & - & - & - & + & + & - & + & - & - & - & - & - & + & - & - \\
\hline 12 & - & - & - & + & + & - & + & - & + & - & + & - & - & + & - \\
\hline 13 & - & - & - & - & + & + & + & - & - & - & - & - & - & - & - \\
\hline
\end{tabular}

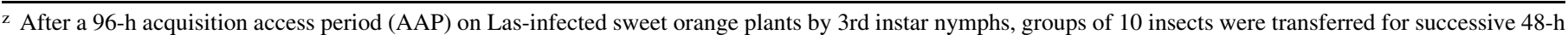
IAPs on healthy test seedlings. The number of days after the beginning of the AAP represents the midpoint of each IAP. Plus (+) and minus (-) symbols indicate transmission and no transmission, respectively. 
as 5 months after inoculation in the $\mathrm{LP}_{\min }$ experiment, whereas only moderate HLB-like leaf mottle symptoms were observed after 6 to 10 months postinoculation in two trials of the $\mathrm{LP}_{50}$ experiment. Thus, it is possible that Las titer and HLB symptoms in the infected plant may evolve faster when the pathogen is inoculated by a larger number of insects, because of the larger number of inoculation points and quantity of inoculum introduced per plant. Rashed et al. (2012) observed a higher titer of ' $\mathrm{Ca}$. L. solanacearum' in potato leaflets inoculated by groups of four than by individual potato psyllids (Bactericera cockerelli Sulc.), but the incubation period of zebra chip disease was not affected by the initial bacterial titer in the inoculated leaflets.

The occurrence of intermittent transmission (interruption in inoculation) through the series of test plants in the $\mathrm{LP}_{50}$ experiment is consistent with previous reports of Las transmission by $D$. citri (Ammar et al. 2013b; Inoue et al. 2009; Xu et al. 1988). In the LP ${ }_{\text {min }}$ experiment, whose test plants were inoculated using groups of psyllids, a higher proportion of infected test plants was observed between 11 and 15 days after onset of the AAP than at later IAPs. The intermittence in transmission by single insects and the decline in the proportion of infected plants in a series exposed to groups of psyllids might be due to a decline in pathogen titer after a period of population growth within the vector, particularly in the salivary glands, which constitute an important transmission barrier for Las and other persistent propagative pathogens (Ammar et al. 2011a; Hogenhout et al. 2008; Purcell 1982; Weintraub and Beanland 2006). If this hypothesis is true for Las in D. citri, it is reasonable to speculate that test plants of the present study may have been inoculated with lower numbers of bacteria after various psyllid transfers, albeit the titer required for the psyllid to be able to inoculate a plant with Las is still unknown. HLB symptoms were not as evident on the test plants of the $\mathrm{LP}_{50}$ experiment as they were for the $\mathrm{LP}_{\min }$ experiment, possibly because of the higher amount of inoculum introduced into the plants for the latter experiment. Considering that plants were kept in the greenhouse and first assayed by qPCR only at 4 months postinoculation, it is possible that the plant eliminated the bacteria inoculated in small titers by a plant defense mechanism, such as calose deposition (Folimonova and Achor 2010; Kim et al. 2009). Ammar et al. (2013a) developed a method in which excised citrus leaves inoculated by psyllids can be maintained in laboratory conditions and tested by PCR within a couple of weeks. On the other hand, the methods adopted in the present work in which whole plants were inoculated and kept in a protected environment for several

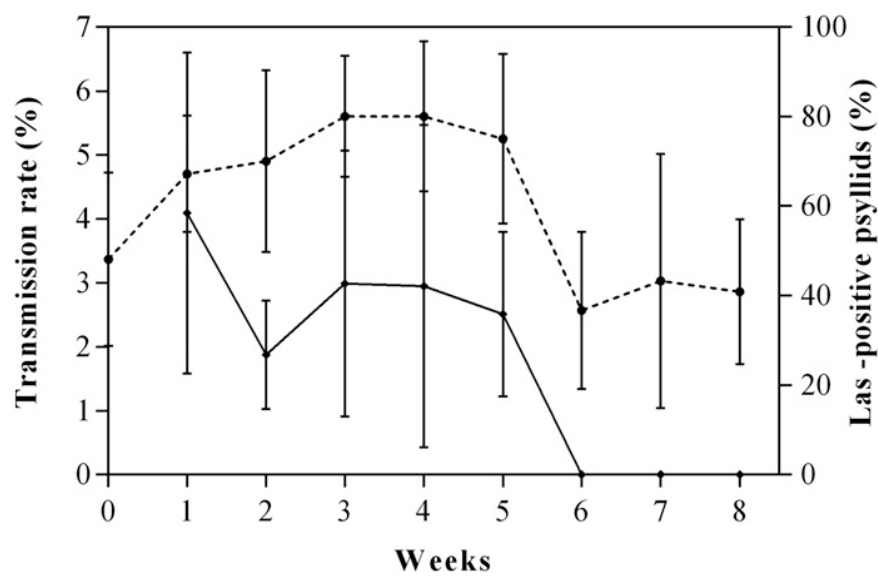

Fig. 5. Persistence of 'Candidatus Liberibacter asiaticus' (Las) transmission by Diaphorina citri. Mean transmission rate (full line) by single psyllids and percentage of Las-positive individuals by qPCR (dotted line) during successive 1 -week inoculation access period (IAPs) on healthy sweet orange seedlings at $25^{\circ} \mathrm{C}$. Because groups of five psyllids were used per seedling during the IAPs, transmission rates by single vectors $(p)$ were estimated as described by Swallow (1985). Bars in each data point represent the standard error of mean for five replicates of the experiment. months allowed reliable detection of systemic and symptomatic infections, because Las was detected by qPCR in leaves sampled above the inoculation point and HLB symptoms developed in most qPCR-positive plants.

We observed that D. citri transmitted Las for 5 weeks after acquisition and the bacterium was detected by qPCR in the psyllids for 8 weeks at $25^{\circ} \mathrm{C}$. Similarly, Xu et al. (1988) reported that D. citri was able to inoculate within 31 days after acquisition in a serial transmission experiment of the HLB agent by single individuals. Considering that psyllids in the present study were older than 40 days by 6 weeks postacquisition, and that the average longevity of $D$. citri is approximately 30 days at $25^{\circ} \mathrm{C}$ (Alves et al. 2014), our results indicate a long-term retention and a persistent relationship of Las with the vector. Hung et al. (2004) observed that the proportion of PCR-positive psyllids remained high (50 to $75 \%$ ) and stable up to 12 weeks postacquisition, which is similar to the range of values (37 to $80 \%$ ) obtained over 8 weeks in the present study. Interestingly, transmission was nil at 6 to 8 weeks from acquisition and the proportion of Las-positive psyllids dropped by half, suggesting that bacterial titer in the vector declines with insect aging. In spite of the evidence of Las multiplication in D. citri, especially when it is acquired during nymphal stages, the proportion of infected salivary glands is lower than that of other psyllid tissue and organs (Ammar et al. 2011a; Inoue et al. 2009; Pelz-Stelinski et al. 2010). A decline in ability to inoculate often occurs with vector aging in persistent transmission, such as that reported for hopper-borne tenuiviruses (Falk and Tsai 1998) and mollicutes (Purcell 1982; Whitcomb et al. 1973).

In conclusion, we have shown that the median latent period of Las in $D$. citri is around 16 to 18 days at $25^{\circ} \mathrm{C}$ and despite the long-term retention of Las in its vector, Las transmission is intermittent and decreases over time. The information on latency duration and retention of Las presented in this paper clarifies important aspects of the transmission biology of this pathogen by $D$. citri, providing additional evidences that the vector-pathogen relationship is persistent and propagative, as proposed previously (Ammar et al. 2011a; Inoue et al. 2009). Further research should address the influence of other factors, e.g., temperature, gender, psyllid biotypes and liberibacter strains on the latency of Las within D. citri. Although Inoue et al. (2009) presented evidence that Las propagates in D. citri after acquisition by nymphs, but not when the adults acquire it, additional studies relating bacterial titers over time are required to characterize propagation of Las in $D$. citri, especially in adults.

The latency period represents a "gap" during which psyllids cannot transmit Las, and thus an opportunity for vector control measures to prevent pathogen spread. In part this explains why secondary spread has been mitigated in citrus orchards regularly treated with insecticides in Brazil (Bassanezi 2013; Bassanezi and Gottwald 2009). However, the long-term persistence of Las in D. citri enables this vector to carry the pathogen over longer distances, promoting primary spread to other citrus farms even on insecticide-treated orchards, and this is currently the major challenge faced by citrus growers.

\section{ACKNOWLEDGMENTS}

We thank J. Balbinote, C. Ferreira, and C. D. Ezequiel for help in DNA extractions and PCR assays during the experiments, as well as C. Jeffries, B. Brodbeck, and G. Teresani for critical review of the manuscript and valuable suggestions. Financial support was provided by Fundo de Defesa da Citricultura (Fundecitrus/Brazil), National Council of Technological and Scientific Development (CNPq/Brazil) and the Citrus Research and Development Foundation (Florida/USA). The second, third, fourth, and fifth authors received $\mathrm{CNPq}$ fellowships.

\section{LITERATURE CITED}

Alves, G., Diniz, A., and Parra, J. 2014. Biology of the huanglongbing vector Diaphorina citri (Hemiptera: Liviidae) on different host plants. J. Econ. Entomol. 107:691-696. 
Ammar, E.-D., Hall, D. G., and Shatters, R. G. 2013a. Stylet morphometrics and citrus leaf vein structure in relation to feeding behavior of the Asian citrus psyllid Diaphorina citri, vector of citrus huanglongbing bacterium. PLoS One 8:e59914.

Ammar, E.-D., Shatters, R. G., Lynch, C., and Hall, D. G. 2011a. Detection and relative titer of Candidatus Liberibacter asiaticus in the salivary glands and alimentary canal of Diaphorina citri (Hemiptera: Psyllidae) vector of citrus huanglongbing disease. Ann. Entomol. Soc. Am. 104:526-533.

Ammar, E.-D., Walter, A. J., and Hall, D. G. 2013b. New excised-leaf method to test inoculativity of Asian citrus psyllid (Hemiptera: Psyllidae) with Candidatus Liberibacter asiaticus associated with citrus huanglongbing disease. J. Econ. Entomol. 106:25-35.

Ammar, E.-D. E., Shatters, R. G. R., and Hall, D. G. D. 2011b. Localization of Candidatus Liberibacter asiaticus, associated with citrus huanglongbing disease, in its psyllid vector using fluorescence in situ hybridization. J. Phytopathol. 159:726-734.

Backus, E. A., Shugart, H. J., Rogers, E. E., Morgan, J. K., and Shatters, R. 2015. Direct evidence of egestion and salivation of Xylella fastidiosa suggests sharpshooters can be "flying syringes". Phytopathology 105:608-620.

Bassanezi, R. B. 2013. Efficacy of area-wide inoculum reduction and vector control on temporal progress of Huanglongbing in young sweet orange plantings. Plant Dis. 97:789-796.

Bassanezi, R. B., and Gottwald, T. R. 2009. Epidemiology of HLB and potential pathways for introduction. Pages 1-11 in: Proc. Int. Workshop on Citrus Quarantine Pest, Villahermosa, Tabasco, Mexico.

Belasque, J., Jr., and Bassanezi, R. B. 2010. Lessons from huanglongbing management in São Paulo state, Brazil. J. Plant Pathol. 92:285-302.

Bonani, J. P., Fereres, A., Garzo, E., Miranda, M. P., Appezato-Da-Gloria, B., and Lopes, J. R. S. 2010. Characterization of electrical penetration graphs of the Asian citrus psyllid, Diaphorina citri, in sweet orange seedlings. Entomol. Exp. Appl. 134:35-49.

Bové, J. 2006. Huanglongbing: A destructive, newly-emerging, century-old disease of citrus. J. Plant Pathol. 88:7-37.

Capoor, S., Rao, D., and Viswanath, S. 1974. Greening disease of citrus in the Deccan Trap Country and its relationship with the vector, Diaphorina citri Kuwayama. Pages 43-49 in: Proc. 6th Conf. Int. Organization of Citrus Virologists, University of California, Riverside, CA.

Carraro, L., Loi, N., and Ermacora, P. 2001. Transmission characteristics of the European stone fruit yellows phytoplasma and its vector Cacopsylla pruni. Eur. J. Plant Pathol. 107:695-700.

Coletta-Filho, H. D., Carlos, E. F., Alves, K. C. S., Pereira, M. A. R., Boscariol-Camargo, R. L., Souza, A. A., and Machado, M. A. 2010. In planta multiplication and graft transmission of 'Candidatus Liberibacter asiaticus' revealed by real-time PCR. Eur. J. Plant Pathol. 126:53-60.

Coletta-Filho, H. D., Daugherty, M. P., Ferreira, C., and Lopes, J. R. S. 2014. Temporal progression of 'Candidatus Liberibacter asiaticus' infection in citrus and acquisition efficiency by Diaphorina citri. Phytopathology 104:416-421.

Da Graça, J. V. 1991. Citrus greening disease. Annu. Rev. Phytopathol. 29: 109-136.

Falk, B. W., and Tsai, J. H. 1998. Biology and molecular biology of viruses in the genus Tenuivirus. Annu. Rev. Phytopathol. 36:139-163.

Folimonova, S. Y., and Achor, D. S. 2010. Early events of citrus greening (Huanglongbing) disease development at the ultrastructural level. Phytopathology 100:949-958.

Gottwald, T. R. 2010. Current epidemiological understanding of citrus Huanglongbing. Annu. Rev. Phytopathol. 48:119-139.

Grafton-Cardwell, E. E., Stelinski, L. L., and Stansly, P. A. 2013. Biology and management of Asian citrus psyllid, vector of the Huanglongbing pathogens. Annu. Rev. Entomol. 58:413-432.

Hall, D. G., and Gottwald, T. R. 2011. Pest management practices aimed at curtailing citrus Huanglongbing disease. Outlooks Pest Manage. 22:189-192.

Hall, D. G., Richardson, M. L., Ammar, E.-D., and Halbert, S. E. 2013. Asian citrus psyllid, Diaphorina citri, vector of citrus Huanglongbing disease. Entomol. Exp. Appl. 146:207-223.

Hocquellet, A., Toorawa, P., Bové, J. M., and Garnier, M. 1999. Detection and identification of the two Candidatus Liberobacter species associated with citrus Huanglongbing by PCR amplification of ribosomal protein genes of the beta operon. Mol. Cell. Probes 13:373-379.

Hogenhout, S. A., Ammar, E.-D., Whitfield, A. E., and Redinbaugh, M. G. 2008. Insect vector interactions with persistently transmitted viruses. Annu. Rev. Phytopathol. 46:327-359.

Huang, C. H., Tsai, M. Y., and Wang, C. L. 1984. Transmission of citrus likubin by a psyllid, Diaphorina citri. J. Agric. Res. China. 33:65-72.
Hung, T., Hung, S., and Chen, C. 2004. Detection by PCR of Candidatus Liberibacter asiaticus, the bacterium causing citrus Huanglongbing in vector psyllids: application to the study of vector-pathogen relationships. Plant Pathol. 53:96-102.

Inoue, H., Ohnishi, J., Ito, T., Tomimura, K., Miyata, S., Iwanami, T., and Ashihara, W. 2009. Enhanced proliferation and efficient transmission of Candidatus Liberibacter asiaticus by adult Diaphorina citri after acquisition feeding in the nymphal stage. Ann. Appl. Biol. 155:29-36.

Kim, J. S., Sagaram, U. S., Burns, J. K., Li, J. L., and Wang, N. 2009. Response of sweet orange (Citrus sinensis) to 'Candidatus Liberibacter asiaticus' infection: Microscopy and microarray analyses. Phytopathology 99:50-57.

Madden, L. V. 1982. Evaluation of tests for randomness of infected plants. Phytopathology 72:195-198.

Maramorosch, K. 1953. Incubation period of Aster yellow virus. Am. J. Bot. 40:797-809.

Moya-Raygoza, G., and Nault, L. R. 1998. Transmission biology of maize bushy stunt phytoplasma by the corn leafhopper (Homoptera: Cicadellidae). Ann. Entomol. Soc. Am. 91:668-676.

Murral, D. J., Nault, L. R., Hoy, C. W., Madden, L. V., and Miller, S. A. 1996. Effects of temperature and vector age on transmission of two Ohio strains of aster yellows phytoplasma by the aster leafhopper (Homoptera: Cicadellidae). J. Econ. Entomol. 89:1223-1232.

Murray, M. G., and Thompson, W. F. 1980. Rapid isolation of high molecular weight plant DNA. Nucleic Acids Res. 8:4321-4326.

Nault, L. R. 1997. Arthropod transmission of plant viruses: A new synthesis. Ann. Entomol. Soc. Am. 90:521-541.

Orlovskis, Z., Canale, M. C., Thole, V., Pecher, P., Lopes, J. R. S., and Hogenhout, S. A. 2015. Insect-borne plant pathogenic bacteria: Getting a ride goes beyond physical contact. Curr. Opin. Insect Sci. 9:16-23.

Parra, J. R. P., Lopes, J. R. S., Torres, M. L. G., Nava, D. E., and Paiva, P. E. B. 2010. Bioecologia do vetor Diaphorina citri e transmissão de bactérias associadas ao Huanglongbing. Citrus Res. Technol. 31:37-51.

Pelz-Stelinski, K. S., Brlansky, R. H., Ebert, T. A., and Rogers, M. E. 2010. Transmission parameters for Candidatus Liberibacter asiaticus by Asian citrus psyllid (Hemiptera: Psyllidae). J. Econ. Entomol. 103:1531-1541.

Purcell, A. H. 1982. Insect vector relationships with procaryotic plant pathogens. Annu. Rev. Phytopathol. 20:397-417.

Purcell, A. H., and Finlay, A. 1979. Evidence for noncirculative transmission of Pierce's disease bacterium by sharpshooter leafhoppers. Phytopathology 69:393-395.

Rashed, A., Nash, T. D., Paetzold, L., Workneh, F., and Rush, C. M. 2012. Transmission efficiency of 'Candidatus Liberibacter solanacearum' and potato zebra chip disease progress in relation to pathogen titer, vector numbers, and feeding sites. Phytopathology 102:1079-1085.

Sengoda, V. G., Cooper, W. R., Swisher, K. D., Henne, D. C., and Munyaneza, J. E. 2014. Latent period and transmission of 'Candidatus Liberibacter solanacearum' by the potato psyllid Bactericera cockerelli (Hemiptera: Triozidae). PLoS One 9:e93475.

Swallow, W. H. 1985. Group testing for estimating infection rates and probabilities of disease transmission. Phytopathology 75:882-889.

Sylvester, E. S. 1965. The latent period of pea-enation mosaic virus in the pea aphid, Acyrthosiphon Pisum (Harris)-An approach to its estimation. Virology 25:62-67.

Teixeira, D. D. C., Saillard, C., Eveillard, S., Danet, J. L., da Costa, P. I., Ayres, A. J., and Bové, J. 2005. 'Candidatus Liberibacter americanus', associated with citrus Huanglongbing (greening disease) in São Paulo State, Brazil. Int. J. Syst. Evol. Microbiol. 55:1857-1862.

Tsai, J. H., and Liu, Y. H. 2000. Biology of Diaphorina citri (Homoptera: Psyllidae) on four host plants. J. Econ. Entomol. 93:1721-1725.

Wang, Z., Yin, Y., Hu, H., Yuan, Q., Peng, G., and Xia, Y. 2006. Development and application of molecular-based diagnosis for 'Candidatus Liberibacter asiaticus', the causal pathogen of citrus huanglongbing. Plant Pathol. 55: 630-638.

Weintraub, P. G., and Beanland, L. 2006. Insect vectors of phytoplasmas. Annu. Rev. Entomol. 51:91-111.

Whitcomb, R. F., Tully, J. G., Bové, J. M., and Saglio, P. 1973. Spiroplasmas and acholeplasmas: Multiplication in insects. Science 182:1251-1253.

Xu, C., Xia, Y., Li, K., and Ke, C. 1988. Further study of the transmission of citrus Huanglongbing by a psyllid, Diaphorina citri Kuwayama. Pages 243-248 in: Proc. 10th Conf. Int. Organization of Citrus Virologists, University of California, Riverside, CA. 